\title{
An experimental and modelling approach to the determination of auto-ignition of diesel fuel, dodecane and hexadecane spray flames at high pressure
}

\author{
Alvaro Diez ${ }^{1}$, Terese Løvås ${ }^{1,2}$ and Roy J. Crookes ${ }^{1}$ \\ ${ }^{I}$ Queen Mary University of London, Mile End Road, London E1 4NS, UK \\ ${ }^{2}$ Norwegian University of Science and Technology, Kolbjørn Hejes vei 1b,7491 Trondheim, \\ Norway
}

Key Words: auto-ignition, modelling, dodecane, hexadecane

\begin{abstract}
In recent years the use of computational simulation tools for combustion research has appeared as a way to reduce time and cost in engine research. These tools face important challenges due to the complexity of the composition of the hydrocarbon petroleum fuels. One of the solutions to this problem is the use of surrogate fuels, with known physical and chemical properties and combustion characteristics similar to real fuels. This paper presents experimental and modelling studies of auto-ignition for long-chain hydrocarbon fuels such as dodecane and hexadecane. Results show a very good agreement for dodecane fuel and hexadecane fuel, with small differences for the latter at lower temperatures which could be caused by the intrinsic nature of the model. These results represent as first step on the development of a surrogate diesel fuel for auto-ignition and soot modelling.
\end{abstract}

\section{INTRODUCTION}

Research on surrogate fuels has grown in recent years as a key area for automotive engine research. Coupled with the use of computational simulation tools it appears to be a way to reduce time and cost in engine research. For combustion simulation of conventional hydrocarbon petroleum fuels, computational tools face enormous challenges because of the complexity of the fuel composition and the lack of kinetic data. The use of surrogate fuels for combustion simulation provides a solution to this problem if they have known physical and chemical properties and combustion characteristics similar to the real fuel.

As part of an investigation for a surrogate diesel fuel, experimental and numerical investigations of ignition characteristics of diesel fuel and a range of linear long-chain alkane hydrocarbons, with similar properties to diesel fuel but simpler kinetic properties have been conducted.

In [1] different mixtures of $\mathrm{n}$-dodecane and hexadecane were employed in an indirect injection diesel engine to examine combustion phasing and stability concluding that large changes in proportions caused modest changes in ignition delays or in the combustion phasing. This was partially explained by the simultaneous variation in mixture properties, which varied considerably with large changes in concentrations, affecting the rate of fuel-air mixing. Thus, the increased time for mixing counteracted against reducing the ignition delay. Optical investigations [2] for reference fuels like n-dodecane have been carried out in a constant volume vessel using flame luminosity and $\mathrm{OH}^{*}$ chemiluminescence in order to determine the influence of auto-ignition, boiling temperature and oxygen content on the emission formation. Previously it was demonstrated that the local fuel/air ratio of the flame at the closest upstream location, known as lift-off location, had a direct effect on soot formation [3, 4]. Due to the higher cetane number of dodecane compared with diesel fuel, the auto-ignition was very short; as a consequence the fuel-air mixture at the lift-off location was rich increasing soot emissions [2].

Different chemical kinetic reaction models have been developed $[5,6,7]$ for the auto-ignition of n-alkane hydrocarbons. However, for higher carbon-containing fuels, the complexity and the size of the chemical mechanism are correspondingly high. The chemical model by Westbrook et al. [5] e.g. accounts for over 2000 species and 8000 reactions, making sure its validity for a wide range of fuels and conditions are met. Yet, in order for such mechanisms to be practical for implementation in simulation software, they are 
commonly reduced to contain only a sub-set of the original reaction paths, as will be discussed here. Both experimental and numerical results are presented of comparisons with n-dodecane and hexadecane fuels in order to develop a validation tool for a diesel fuel surrogate mechanism.

\section{EXPERIMENTAL SETUP}

All experiments were carried out in an optical combustion chamber. This facility is essentially an auxiliary chamber fitted with inspection fused quartz windows. The optical chamber is connected via a passage to one combustion chamber of a four-cylinder diesel engine in which a flat-top piston replaces the standard piston. The chamber contribution to the clearance volume corresponds to the removed piston bowl. The engine is run on standard diesel fuel, using the other three cylinders fed from a standard fuel pump to establish the speed while motoring the optical chamber. The chamber is fitted with a piezoelectric pressure transducer for cylinder pressure and energy conversion rate analysis. To maintain the clearance volume the optical chamber has diameter $34 \mathrm{~mm}$. Fig. 1 shows the schematic diagram of the optical access chamber and Table 1 shows the engine specifications and compression ratio after the modification.

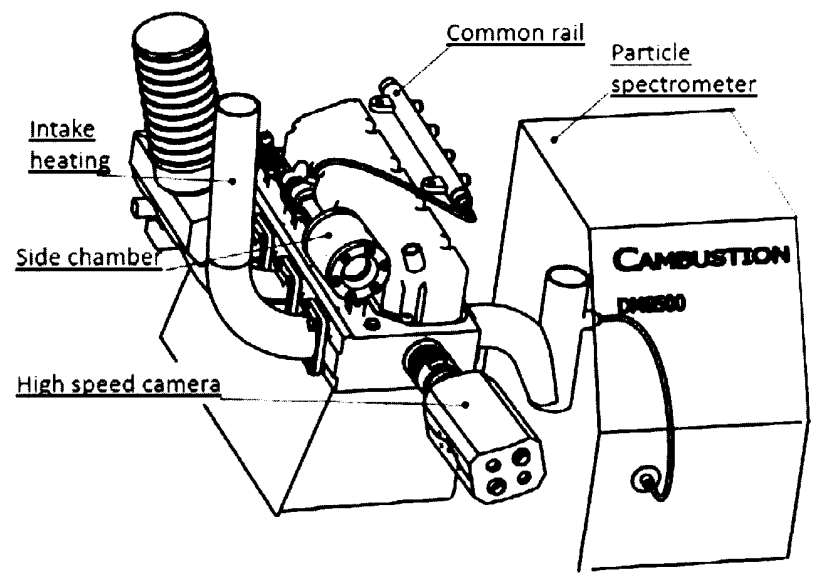

Fig. 1 Schematic diagram of the optical combustion chamber

The chamber is fitted with a high pressure common rail injection system capable of injection pressure of up to $160 \mathrm{MPa}$. The rail is fitted with a pressure sensor, the signal of which is sent to a custom built ECU to control the injection pressure. The common rail has four outlets, three of which are blanked off while the remaining one connects it with the injector. Table 2 shows the specification of the injector used in this study. A LabVIEW custom built program controls the pump and the injector driver The ECU is fed with the shaft encoder and top dead centre (TDC) signals and controls injection timing and duration.
Table 1 Engine specification

\begin{tabular}{cc}
\hline \multicolumn{2}{c}{ Ford In-line O.H.V. (modified) Engine } \\
\hline Bore & $93.67 \mathrm{~mm}$ \\
Stroke & $90.54 \mathrm{~mm}$ \\
Connecting rod length & $0.1539 \mathrm{~m}$ \\
Cylinder capacity & $624 \mathrm{~cm} 3$ \\
Compression Ratio & $16.95: 1$ \\
Engine Speed for Testing & $1000 \mathrm{r} / \mathrm{min}$ \\
\hline
\end{tabular}

Table 2 Injector characteristics

\begin{tabular}{cc}
\hline \multicolumn{2}{c}{ Siemens Lynx Injector } \\
\hline Injection Pressure & $80 \mathrm{MPa}$ \\
Number of Holes & 7 \\
Cone Angle & $152^{\circ}$ \\
Hole Diameter & $110 \mu \mathrm{m}$ \\
Nozzle flow & $320 \mathrm{cc}$ \\
Type & Microsac \\
\hline
\end{tabular}

\section{Cylinder pressure and optical techniques}

For the fuels investigated, different injection timings were analysed recording the cylinder pressure data and calculating the ignition delays after determining Start Of Injection (SOI) and Start Of Combustion (SOC). From the cylinder pressure data, the bulk gas temperature was calculated as well as the energy conversion rate. Analysis of the pressure traces of firing cycles revealed that after reaching peak pressure, a pressure drop was experienced, which was more prominent at earlier injection timings. This phenomenon appears to be linked with the piston motion in the main cylinder. The energy conversion rate calculations were distorted and the usual information on premixed and diffusion combustion phases was not recovered.

A high speed video camera was used to record the fuel spray during the injection period and combustion images. In order to visualize the injected spray, a high output fibre optic illuminator system was employed. A Phantom V 4.3 digital camera equipped with a high speed colour CMOS sensor was used which can record up to 90000 frames per second. The recording speed for this study was $6000 \mathrm{fps}$ which correspond to 1 crank angle per frame. The image resolution was $256 \times 256$ pixels. A Nikon $60 \mathrm{~mm}$ f. 2.8 lens was mounted on the camera. Thus ignition delays were measured and compared with those calculated from the cylinder pressure data.

At this framing speed, the sprays were short lived prior to combustion but the general profile was comparable. Further tests with optimum illumination and faster recording are planned to examine this more extensively. 
Table 3 Chemical properties and physical characteristics of the fuels at standard atmospheric conditions

\begin{tabular}{cccc}
\hline Fuels & Diesel & Dodecane & Hexadecane \\
\hline Chemical formula & $\mathrm{C}_{\mathrm{n}} \mathrm{H}_{1.8 \mathrm{n}}$ & $\mathrm{C}_{12} \mathrm{H}_{26}$ & $\mathrm{C}_{16} \mathrm{H}_{34}$ \\
Density $/ \mathrm{kg} / \mathrm{m}^{3}$ & $827-840$ & 749 & 773 \\
Lower heating value $/ \mathrm{MJ} / \mathrm{kg}$ & 42.5 & $44.5[9]$ & $44.3[9]$ \\
Cetane number & 52 & $85[10]$ & $100[10]$ \\
Initial boiling point $/{ }^{\circ} \mathrm{C}$ & 169 & 216 & 287 \\
Injection quantity $/ \mathrm{mg} / \mathrm{st}$ & 5.6 & 5.0 & 5.2 \\
\hline
\end{tabular}

Fuels investigated

In this investigation $\mathrm{n}$-dodecane and hexadecane fuels were tested. The single molecule long-chain hydrocarbons were chosen as one of the main components of diesel fuel. The injection duration was kept constant and due to the different mixtures' densities, different amounts were injected. Table 3 shows fuel properties of the reference fuels.

\section{AUTO-IGNITION MODEL}

The simulations are performed using a direct injection (DI) stochastic reactor engine model (SRM) available in the reactor simulation tool DARS [8]. The DI-SRM module is based on a stochastic distribution of properties in the domain which is important when considering direct injection systems. The model accounts for free mixing of the particles and heat transfer to the walls. As fuel is injected according to an injection profile determined by the experiments, new particles containing fuel and gas mixture are added. It should be noted that the fuel is assumed fully evaporated at the time of injection, which may cause some enhancement of the calculated ignition times compared to experiments. This is however considered to be small compared to the total ignition delay. All engine specific data are set according to the experimental optical combustion chamber.

Although great efforts have been made to develop auto-ignition mechanisms for a variety of fuels, not all models cover the range of single component fuels available. Moreover some of these models have been only validated under specific conditions which sometimes vary substantially from engine-like conditions.

In order to simulate different types of fuels, a detailed mechanism for n-alkanes is chosen. The mechanism by Westbrook et al. [5] is such a mechanism. It contains oxidation paths for both n-dodecane and $\mathrm{n}$-hexadecane. It includes 8157 reaction paths for 2115 species. However, much computational resources are required when employing such a large mechanism in a stochastic reactor model. It has therefore been reduced for the purpose of the current simulations to only 658 species and 2874 reactions by means of a combined reaction flow and sensitivity analysis [11]. This approach outlines major reaction paths at the same time as important species are identified according to the species sensitivity towards chosen combustion targets. In this work the combustion targets were temperature and $\mathrm{OH}$ simultaneously. The final output of the analysis was a ranking according to necessity for a reliable prediction of the important parameters. Its validity is tested and confirmed for a wide range of condition relevant for the engine conditions in a rapid compression machine module in DARS. Due to space restrictions this will not be discussed in further detail here. However, reduction of available detailed schemes for the model fuels is an important part of the current work and is the subject for parallel publications.

Ignition timing is determined from the $\mathrm{OH}$ profiles. However, a double-peaked $\mathrm{OH}$ profile is observed, especially for $\mathrm{n}$-dodecane. This is believed to be a result of the stochastic distribution of properties in the DI-SRM, where the hotter spots will initiate ignition. Both these peaks have been considered for ignition delay, as will be discussed below in relation to the observed ignition delay times. Fig. 2 shows the $\mathrm{OH}$ profile for $\mathrm{n}$-dodecane at $\mathrm{SOI}$ 30 CA BTDC, Tair $752 \mathrm{~K}$.

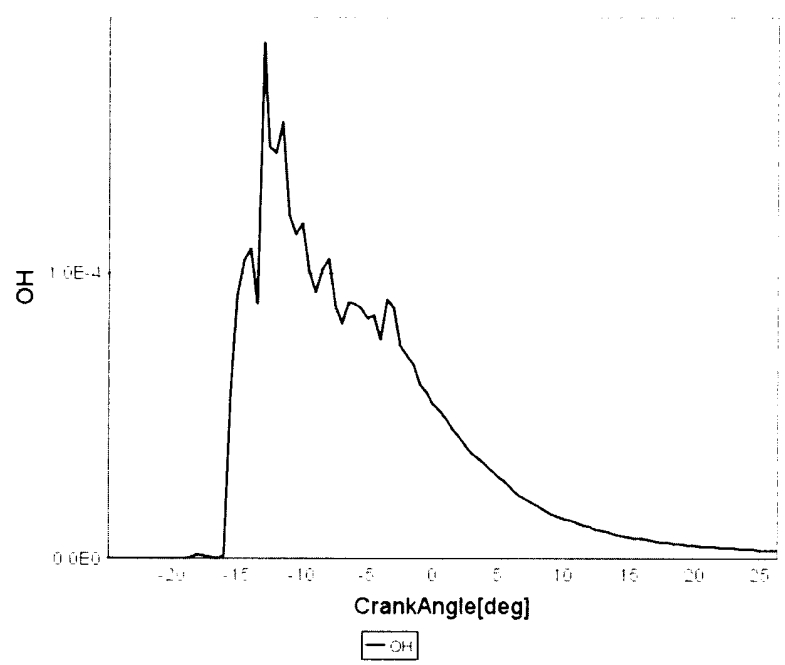

Fig. 2 Typical $\mathrm{OH}$ profile for one condition for n-dodecane 800 bar, SOI 30 CA BTDC, $\mathrm{T}_{\text {air }} 752 \mathrm{~K}$.

\section{RESULTS AND DISCUSSIONS}

The ignition delay was determined from the cylinder pressure as well as from the high speed imaging videos. Fig. 3 illustrates the pressure traces for diesel fuel, dodecane and hexadecane fuels for one of the conditions investigated as well as the injection signal for this condition. For hexadecane fuel, SOI was delayed $2 \mathrm{CA}$ with respect to the signal, this was observed in all high speed videos and it was probably due to some properties like viscosity, bulk modulus or lubricity affecting the needle movement in the injector. Therefore taking into account the injection delay, hexadecane shows the 


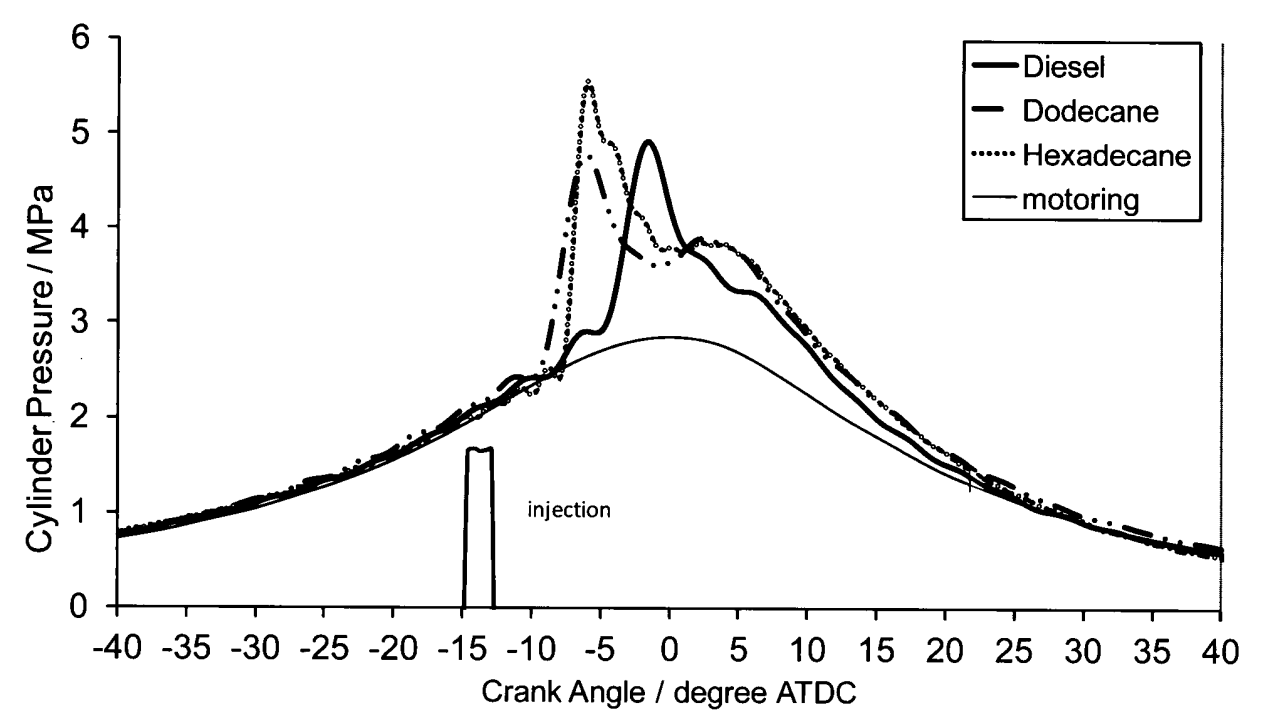

Fig. 3 Pressure traces for all fuels investigated at 800 bar injection pressure and injection timing

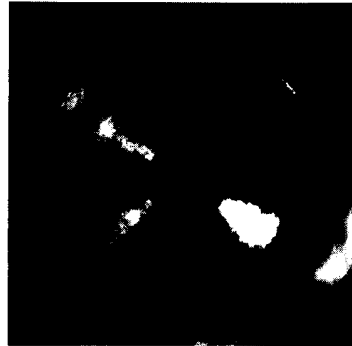

SOI $15^{\circ} \mathrm{CA} B T D C$

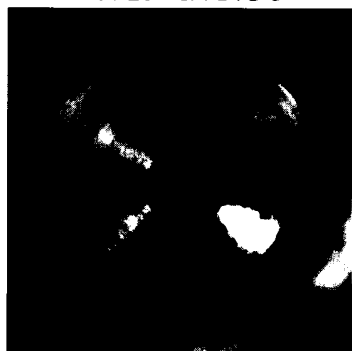

$9^{\circ} \mathrm{CA} B \mathrm{BTDC}$

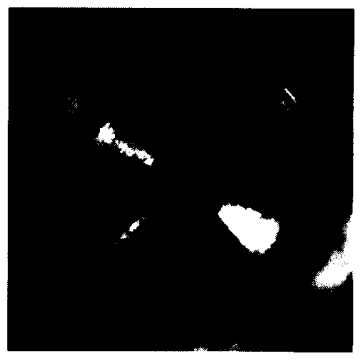

$14^{\circ} \mathrm{CA}$ BTDC

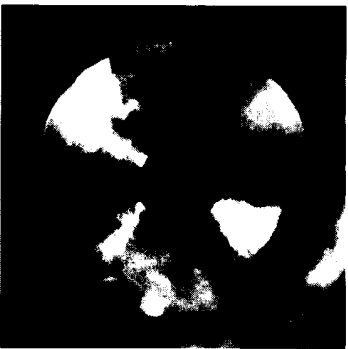

$8^{\circ} \mathrm{CA} \mathrm{BTDC}$

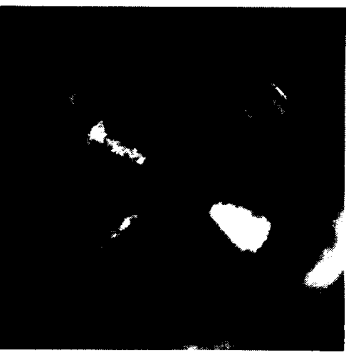

$13^{\circ} \mathrm{CA} B$ BDC

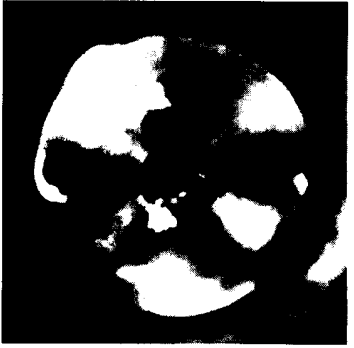

$7^{\circ} \mathrm{CA} B \mathrm{BTC}$

Fig. 4 Injection and start of combustion for dodecane fuel at 800 bar injection pressure, $T_{\text {air }} 925 \mathrm{~K}$ at $6000 \mathrm{fps}$

shortest ignition delay, followed by dodecane and diesel reflecting the variation of cetane number of the fuels. It is interesting to notice, that not only the ignition delays are different but the combustion process as well. Thus hexadecane experienced a more rapid pressure rise reaching a higher peak pressure indicating that more fuel was premixed during the ignition delay, since its density is higher than dodecane and more fuel was injected and ready to burn in the premixed phase.

Dodecane, however, showed pressure traces more similar to diesel in terms of premixed and mixing controlled phases differing only on ignition delay as mentioned before.

Fig. 4 shows the injection process and start of combustion for dodecane fuel at SOI 15 CA BTDC.

It was found that the ignition delay calculated from the cylinder pressure and from luminosity was not exactly the same. SOC from cylinder pressure data was determined as the start of high temperature reaction, however for early injection timings (at lower temperatures), the camera probably could detect chemi-luminescence from the cool flame reaction at specific ignition sites. For later injection timing, (at higher temperatures) combustion starts at sites throughout almost the whole of the chamber and is registered readily by the pressure sensor. So the difference between ignition delay from luminosity and from cylinder pressure detection is higher at early injection timings. This phenomenon was observed for all the fuels investigated.

Experimental results of dodecane and hexadecane are compared with diesel fuel for which no such mechanism is yet available.

Fig. 5 presents a comparison of ignition delay for 
diesel fuel and dodecane using luminosity data from the high speed camera and also for diesel using combustion chamber pressure records. The error bars for the former for diesel fuel indicate the precision by which this parameter can be estimated from the frame sequences at the particular speed selected. Repeated observations did not differ beyond this range.

When using the DI SRM Model for the determination of auto-ignition from the $\mathrm{OH}$ signal, two peaks were observed, an initial small peak signifying $\mathrm{OH}$ initiation, usually a few crank angle degrees in advance with respect of the main $\mathrm{OH}$ rise. Both ignition delays, from $\mathrm{OH}$ initiation and $\mathrm{OH}$ rise are plotted with the experimental data in Fig. 5 and show an agreement with the experimental data. The ignition delay calculated from the $\mathrm{OH}$ initiation more closely reflects the experimental results and has therefore been adopted for this purpose hereafter in this paper. The ignition delay difference between diesel fuel and dodecane probably reflects the cetane number and its chemical basis, for which dodecane is considerably higher than diesel.

Fig. 6 illustrates the comparison between ignition delay for diesel fuel and hexadecane (cetane) obtained in each case by both combustion chamber pressure measurement and from high speed camera records. The difference between the data for the two fuels reflects the variation of the cetane number, for which hexadecane is the upper standard.

Comparison with predictions for hexadecane using $\mathrm{OH}$ initiation to signify ignition shows that the magnitude of the delay is similar and its temperature variation is represented by the SRM model. There is good agreement at the latter injection timings where the cylinder temperature is higher. For earlier injection timings, at lower temperature, the ignition delay predicted by the model is shorter than observed experimentally, which could be due to the assumption that the fuel is fully evaporated at the time of injection. Experimentally, fuel atomizes and vaporizes before mixing with the air. At this particular case, these processes take longer than at higher pressure and temperature leading to a difference between the model and the experimental results.

This phenomenon was not observed in the dodecane mechanism at lower temperatures in the SRM model. One reason could be the lower vaporization point of dodecane leading to a small difference between the model and experiments.

\section{CONCLUSIONS}

In this study, experimental and numerical investigations of auto-ignition for dodecane and hexadecane were undertaken to develop a validation tool for chemical kinetic data using diesel fuel surrogate mechanisms. For this purpose experiments were carried out in an optical combustion chamber and these results were compared with stochastic reactor engine models. The mechanism used was developed by Westbrook et al. [5] meant for large n-alkanes for up to n-hexadecane.

The DI SRM model was applied to determine auto-ignition of $\mathrm{n}$-dodecane and compare it with the experimental data. The predicted ignition delay from $\mathrm{OH}$ initiation showed good agreement with the ignition delay from the luminosity experiments.

\section{Ignition delay in optical chamber for diesel and $\mathbf{n}$-dodecane}

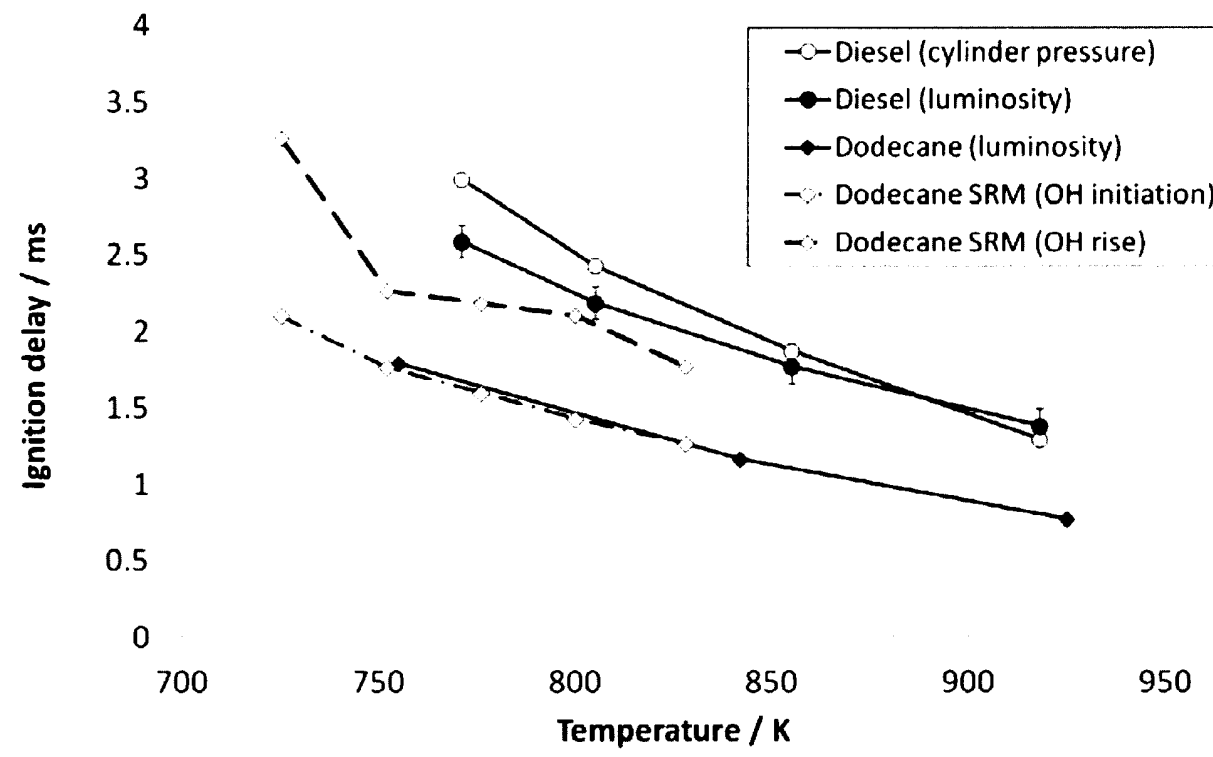

Fig. 5 Ignition delay of diesel fuel and dodecane fuel 


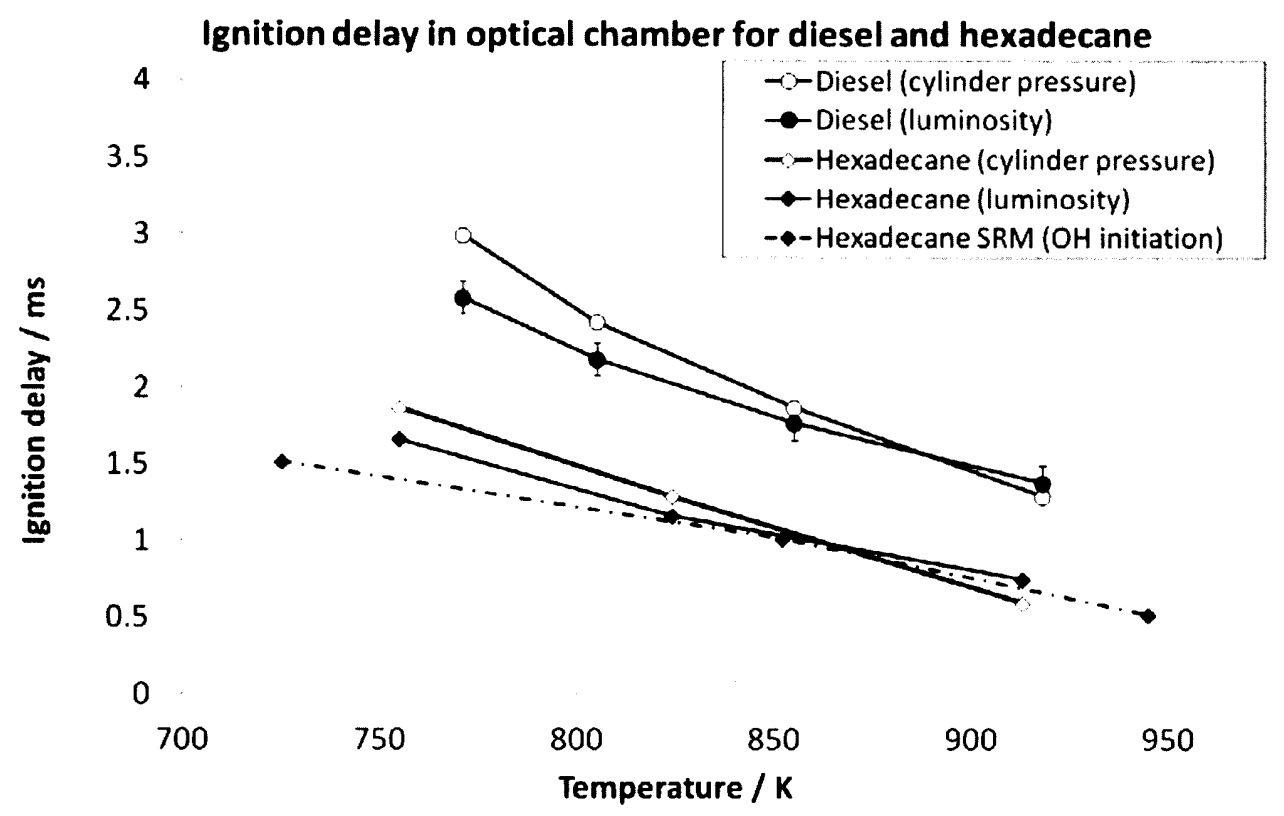

Fig. 6 Ignition delay of hexadecane and diesel fuels

For hexadecane, the numerical results were close to the experimental ones. At lower temperatures the ignition delay predicted by the model was shorter than calculated experimentally, which could be caused by the assumption that the fuel is fully evaporated at the time of injection

A reduced mechanism was tested and compared with experimental data for auto-ignition of dodecane and hexadecane. It was observed that although this mechanism was performing well compared with the detailed mechanism, it still represents differences when employed for conditions outside its validation ranges and further developments are necessary in the search for practical numerical models that can predict auto-ignition for a variety of fuels over different engine conditions.

In terms of providing suitable surrogate diesel fuels for modelling, the ignition delay trends of the tested fuels were comparable with diesel fuel differing in magnitude in accord with cetane number.

\section{REFERENCES}

[1] A. Mathes, J. Ries, P. Caton, J. Cowart, D. L. Prak, and L. Hamilton, Society of Automotive Engineers, SAE Paper 2010-01-2188, 2010.

[2] P. Hottenbach, T. Brands, G. Grnefeld, A. Janssen, M. Muether and S. Pischinger, Society of Automotive Engineers, SAE Paper 2010-01-2193, 2010.

[3] D. Siebers, and B. Higgins, Society of Automotive Engineers, SAE Paper 2001-01-0530, 2001.

[4] L. M. Pickett and D. L. Siebers, Combustion and Flame 138(1-2): 114-135, 2004.
[5] C. K. Westbrook, W. J. Pitz, O. Herbinet, H. J. Curran and E. J. Silke, Combustion and Flame 156, 181 - 199, 2009.

[6] J. Andrae, D. Johansson, P. Bjørnbom, P. Risberg, and G. Kalghatgi, Combustion and Flame 140, 267 - 286, 2005.

[7] H. Wang, E. Dames, B. Sirjean, D. A. Sheen, R. Tangko, A. Violi, J. Y. W. Lai, F. N. Egolfopoulos, D. F. Davidson, R. K. Hanson, C. T. Bowman, C. K. Law, W. Tsang, N. P. Cernansky, D. L. Miller and R. P. Lindstedt, JetSurF version 2.0, September 19, 2010 (http://melchior.usc.edu/JetSurF/JetSurF2.0).

[8] DigAnaRS, http://www.diganars.com/, Dars, 2011.

[9] E. Sagadeev, R. Kafiatullin, V. Sagadeev and V. Sagadeev, Theoretical Foundations of Chemical Engineering 37, 2003, 92-95.

[10] B. Creton, C. Dartiguelongue, T. de Bruin and H. Toulhoat, Energy \& Fuels 24 (2010) 5396-5403.

[11] H. Soyhan, P. Amnéus, F. Mauß, \& C. Sorusbay,. Society of Automotive Engineers, SAE Paper No 1999-01-3484, 1999. 